\title{
Evaluation of board performance in Iran's universities of medical sciences
}

\author{
Haniye Sadat Sajadi ${ }^{1}$, Mohammadreza Maleki ${ }^{2}$,Hamid Ravaghi², Homayoun Farzan ${ }^{3}$, Hasan Aminlou ${ }^{3}$, \\ Mohammad Hadi ${ }^{4}{ }^{*}$
}

\begin{abstract}
Background: The critical role that the board plays in governance of universities clarifies the necessity of evaluating its performance. This study was aimed to evaluate the performance of the boards of medical universities and provide solutions to enhance its performance.

Methods: The first phase of present study was a qualitative research in which data were collected through faceto-face semi-structured interviews. Data were analyzed by thematic approach. The second phase was a mixed qualitative and quantitative study, with quantitative part in cross-sectional format and qualitative part in content analysis format. In the quantitative part, data were collected through Ministry of Health and Medical Education (MoHME). In the qualitative part, the content of 2,148 resolutions that were selected by using stratified sampling method were analyzed.

Results: Participants believed that the boards had no acceptable performance for a long time. Results also indicated the increasing number of meetings and resolutions of the boards in these 21 years. The boards' resolutions were mostly operational in domain and administrative in nature. The share of specific resolutions was more than the general ones.

Conclusion: Given the current pace of change and development and the need to timely respond them, it is recommended to accelerate the slow pace of improvement process of the boards. It appears that more delegation and strengthening the position of the boards are the effective strategies to speed up this process.

Keywords: Governing Board, Task Performance, Evaluation, Academic Medical Centers

Copyright: (C) 2014 by Kerman University of Medical Sciences

Citation: Sajadi HS, Maleki M, Ravaghi H, Farzan H, Aminlou H, Hadi M. Evaluation of board performance in Iran's universities of medical sciences. Int J Health Policy Manag 2014; 3: 235-241. doi: 10.15171/ijhpm.2014.86
\end{abstract}

\section{Article History:}

Received: 15 August 2014 Accepted: 10 September 2014 ePublished: 14 September 2014

\section{Key Messages}

Implications for policy makers

- Given a lack of concrete evidence of the medical universities' board effectiveness, developing a comprehensive and systematic system to evaluate the performance of these boards is paramount.

- More incentives including passing legal requirements, giving awards, allocating more funds, and so on. are needed to motive all universities for more participation in the evaluation process of their boards.

- To improve the effectiveness of a medical university's board and to strengthen its role, increasing the board's authority, revising the board's responsibilities, and informing about the role and mission of the university board are desired.

\section{Implications for public}

Performance evaluation of the university's board is becoming increasingly important as governing boards are required to demonstrate their accountabilities. If a systematic approach is employed to evaluate the university's board performance, the higher and lower performing boards will be identified as well as the facilitators and barriers affecting the board performance. Understanding these boards and factors helps benchmark for best practices and improve performance which leads to the best management practices for effective and efficient achievement of the university's goals.

\section{Introduction}

Given the World Health Organization's (WHO) definition of healthcare systems, which defines it as comprising all the organizations, institutions and resources that are devoted to producing health actions (1), and the structure of health system in Iran (2), the University of Medical Sciences (UMS) is the main part of the healthcare system at operational level.
The UMSs play the leading role in provision of health services and educating medical sciences. The UMS is a collaborative of organizations, including one or more accredited medical schools and one or more affiliated hospitals, where many of the medical staff physicians are faculty members. At the UMS, clinical care is delivered, undergraduate and graduate medical education is conducted, and biomedical and other research 
is carried out. As emphasized repeatedly in the literature, these kinds of universities are among the largest and most complex organizations, mainly because of the formidable diversity in their three core missions. It is this three-fold mission (healthcare, education, and research) that makes the management of UMSs multifaceted and challenging $(3,4)$. Because the way a university is organized to manage its internal and external operations determines how effective it is in fulfilling its mission.

Organizational success of such complex structures primarily involves use of the best management practices for effective and efficient achievement of the predetermined goals. The review of literature showed that given the changes imposed by the universities, one of the best ways to manage UMS is through the boards $(5,6)$. Furthermore, various studies have revealed the importance of university autonomy and demonstrated the positive effects of institutional autonomy. The freer a university is to respond to the rapidly changing environmental forces and to mobilize and reallocate internal resources, the more efficient and effective they are in accomplishing their goals. In higher education, governance through the board is a proven strategy to preserve institutional autonomy, promote institutional agility, and enhance strategic goal attainment (7-9).

The important role that the board plays in UMS explains the importance and necessity of evaluation the board performance. Measuring board performance is obviously a difficult activity (10), however, it can help a board to identify its strength and weakness and help them to adopt required actions that may result in improving effectiveness and/or efficiency (10-13). Therefore, improving the board's performance is likely lead to greater university effectiveness.

Review of literature indicates few studies on the subject in Iran, especially in UMSs. Therefore, it is needed to study performance of these boards and propose solutions to improve their performance. In response to this need, the present study attempted to firstly, examine the perspective of board informants about the performance changes of the boards and influential factors from. Secondly, it evaluated performance of the boards of UMS in two fronts of quantity of meetings and resolutions, and quality of resolutions passed in the past twenty years.

\section{Methods}

\section{Phase one}

To gain more in-depth understanding of experiences of relevant participants a qualitative approach was employed. We selected participants from individuals who: 1) had served as university board member; 2) involved with the university board performance evaluation and; 3) had experience about the university board's affairs; and 4) were consent to participate in the study. Given these criteria, three groups of participants identified for interview who were the level I (top level) including staff and consultants who have worked with the board in Ministry of Health and Medical Education (MoHME), Ministry of Sciences and Technology and other national institutions, level II (middle level) including university's board members and the board secretaries of the universities and level III (bottom level) including the vicechancellors of the universities. The experiences and viewpoints of these participants, who were directly and indirectly affected by the boards' performance, provided a good opportunity for us to carry out a comprehensive evaluation. To ensure that a diverse set of individuals was included in our sample, purposeful sampling was used.

Data were gathered using 37 semi-structured face-to-face interviews. In order to maintain stability and avoid any potential bias, the topic guide was used to conduct interviews. To reduce narrative errors, all interviews were conducted by one of the research team (HSS). Participants were informed about study details in advance. Interviews took between 25-30 minutes to complete and were conducted at the workplaces of interviewees. All interviews were audio-typed and transcribed. All ethical issues were considered assuring confidentiality. Upon transcription, texts were reviewed by participants and authenticity of the statements got confirmed. Data gathering was lasted until data saturation at which no new information or themes were observed in the data. This occurred when themes identified. Data analysis was performed using thematic analysis method. Codes and themes were derived from original data. Content was encrypted under 2 overall themes. To increase validity, triangulation methods were used. Accordingly, some interviewees were informed of results of the analysis and their suggestions and opinions were inserted in the final analysis. In presenting the data in results, all quotations have referred by $\mathrm{P}$.

\section{Phase two}

Mixed qualitative and quantitative approach was used in this phase. The quantitative part was cross-sectional. In this part, the number of meetings and resolutions of UMSs during 1992-2012 were collected through MoHME. The statistical population included all universities of the MoHME that at the time of this study that had independent boards ${ }^{1}$, numbering 52 in total. The trend analysis was done using Mann-Kendall test with $5 \%$ significant level.

To evaluate the resolutions quality, content analysis with categorical approach was used. Categorization was done using a framework developed in accordance with previous studies and experts' opinions. In this framework, the content of every resolution was analyzed in three dimensions as follows:

1. Domain (strategic and operational): Strategic resolution was a resolution that: 1) focused on long term decisions, 2) was competitive and brought more competitive merits for the university, and 3) was vital for the university survival. Operational resolution was that decision which concentrated more on operating and executive matters of providing health and education services and also had a short time horizon.

2. Nature (higher education, health, administration): If a resolution related directly to decision-making about educational, researching and student affairs, it would

1. Given the Act of the university board formulation in Iran, which says the requirements of boards' member, independent board is a board that has a majority of outside members who are not affiliated with the university president and have minimal or no business dealings with the university to avoid potential conflicts of interests. 
categorized in higher education resolutions. The resolution relating directly on providing healthcare services (e.g. treatment care and preventive care), was put in health resolutions. The administrative one was a resolution related mainly to managing university resources, including human, financial and physical resources.

3. Source (general and specific): If the agenda of a resolution had come from the MoHME as a common agenda for all UMSs, that resolution was a general one. While a resolution that its agenda had proposed by own individually university, was a specific one.

This framework was used in a small part of the sample, in preliminary format (as a pilot study) and its potential errors were resolved, and the final version was used as guideline for separation of resolutions.

The statistical population for qualitative part included all resolutions of UMSs. Sample size was found 2,148.

\section{Results}

Phase one

a. Performance changes of the Universities of Medical Sciences boards and factors affecting it

All participants were in agreement on the point that although the boards officially began their work in 1992, for the first decade, they were not very active. In their perspectives, the limited activity of the boards in this period was not due to legal impediments. Because the legal impediments created post 1979 by the bill dissolving university boards had been somewhat decreased by the Act of establishment of the boards in 1988: "We don't have a major legal problem with the boards, the current Act of the Boards gives them extensive authority, which is called they have absolute authority" [P35]. Most participants blamed intra- and extra-organizational ignorance toward the subject of managing universities through boards as the main impediment to their activities in the first decade of establishment. In the intra-organization part, not only had the UMSs not understood the real position and mission of the boards, but also they were not fully aware of their responsibilities and authorities. UMSs continued to adhere to the current rules and regulations of the land for management of university affairs. This weakness created a non-confidence atmosphere in the MoHME officials to delegate full authority to the boards. In the extra-organizational part, lack of awareness of some organizations, especially regulatory organizations, of the position of the boards, equating UMSs to others organizations was identified as the main impediment to the boards to carry out their duties. "Although these were previous experiences, yet again there was ignorance about the issue in the whole body of universities, even in higher education. Current rules and regulations were institutionalized in universities. I mean, in a basic and institutionalized way, the thought of autonomy of universities or thought of boards managing universities hadn't spread to all parts of the university. This causes that the acceptance of boards had lowered the universities on the one hand, and on the other, reduced the confidence of trustees to delegate affairs to the boards. These, together with ignorance of the subject at the highest level of the government caused seeing a duality in regulations... All these made having boards, at all, be only partially established" [P30]. Participants believed, gradually, in time, and with intervention of some factors, performance of the boards had improved. These participants regarded the first spurt of activity of the boards to have taken place toward the end of first decade of establishment that is in 2000. They claimed that the dominance of paradigm of university autonomy and further understanding of the position of the boards led to activation of these boards. Furthermore, some structural modifications in the body of MoHME, and establishment of a place for the affairs of the boards, also played a role in improving their activity level. "It was the year 2000, when some changes happened in the structure of Ministry of Health, in this new set-up, the managing directorate was changed to coordinating affairs viceroy. This change of position, with further authority for managing affairs of the boards, was able to make them more active" [P3].

The second spurt of boards' activity, with more intensity, was reported in 2006. As participants stated many factors were involved in this spurt of activity. Firstly, passage of nearly 15 years had helped better understanding of position of the boards both by the UMSs and by MoHME. Secondly, communicating and frequent meetings with relevant organizations, especially, regulatory bodies in order to justify the position of university changed extra-organizational perception and attitudes toward the boards. But, the most important factor was ratifying Act of The Fourth Economic, Social, and Cultural Development Program in 2005. This Act was able to have a huge share in further understandings of position and mission of the boards by intra-and extra-organizations, and by stating cases and examples of authorities of the boards justified their legal status. "It was the second round, the round I think the Fourth Program was passed. It was in the Act, the Legal Act, it was ratified by the Parliament, as well as the idea of, in fact, somehow of the Cultural Revolution Council too. It turned to a legal resolution, perhaps, it could be called, since that date, the second phase of the boards, could be said, and the boards are shaping up" [P10]. Majority of participants emphasized the spurt of activity of boards in 2010. These interviewees stated three factors that caused performance improvement of the boards in that and the following years. The first factor was strengthening the boards in UMSs, which was provided by passing the comprehensive regulation of management of universities and higher education in 2010. Stressing and legally increasing the authorities of the boards was the second factor, created by article 20 of the Fifth Economic, Social, and Cultural Development Program. Increased extent of authority of the boards, particularly in trading affairs, which was not foreseen in the Fourth Program, and making the boards accountable emphasized the position and role of the boards even further. "It's in the fifth Program that is a little stronger than the Fourth, and in any case, it is implemented in the universities, and it could be said again, it is a progressive Act" [P18]. The third factor was associated with the central coordination of activities of the boards at the national level. Many attempts were made during this period in different forms such as establishment of secretariats of the boards in UMSs which caused flourishing 
of the boards and improved their activities. "But, 2.5 years since Dr... came, changes can be easily seen, I compare and say that these 2.5 years was really an extraordinary period for the boards" [P11].

b. Strengths and weaknesses in current performance of Universities of Medical Sciences boards

Most participants reported the current performance of the boards relatively satisfactory and believed, even though the performance, compared to the past, had improved, it is still far from the satisfactory level of realization missions destined for the boards. "I say, it has had a growing trend, a growing trend, that role of the boards in universities becomes more prominent, more, but it is far from maturity yet, to the point that boards would be the places for decision-making of universities, it is far from that yet" [P10].

Participants believed that the most strength of the current performance of boards is the increase in number of meetings that provided the boards' sharing and intervention in the governance of university. Relative improvement of quality of resolutions with a bias toward strategic resolutions was identified as other strength. Participants reminded that in tandem with time and understanding position of the boards, their resolutions have distanced themselves from operational domains and increasingly moved toward strategic subjects. They predicted a greater tendency toward strategic domains, with the emphasis and support newly provided by the MoHME for holding meeting without the need for presence or approval of the MoHME. "It's been better in the past couple of years, more planning in past couple of years, at least, in the framework of role of the board, in subjects like operational planning, performance monitoring, they are better now, and present some points of views, number of meetings has grown, at least 4 times per year they hold meetings" [P20].

"Employment regulations are written, trade regulations have been signed, so universities have greater authority in budgetary matters. Of course in some areas, it has been very little, and of course now we are raising it, now this subject means entering the large scale university plans" [P23].

The most important weakness in performance of boards related to quality of decision-making (resolutions) in two dimensions of nature and source. Participants stated that the majority of decisions made by the boards related to administrative affairs. Decisions were less biased toward two main missions of Medical University (that is: medical education and provision of health services). These participants considered this to be due to the job description and duties determined for the boards, which focuses more on the managerial aspects of UMSs. "Unfortunately, the boards are weak in areas of education and health services, and I'd say that university chancellors don't like it either for the boards to interfere in these matters, anyway, they like to resolve financial problems of their organization, that is why, often chancellors bring up their financial problems - and don't enter these areas much, not at all, and this is a massive weakness that our boards are boards that only focus on finances and management" [P24]. In addition, participants reported a reduction in specific resolutions and an increase in general resolutions with time.
"Its volume is getting bigger; being more or less depends on its necessity" [P16]. Most participants regarded this change as a weakness. Because they believed the enforced guidelines from the MoHME could distance boards from strategic subjects, depriving them of thought and innovation, and make members less motivated to contribute to solving problems of the UMSs, prevent constructive discussions in meetings, and reduce efficacy of meetings, and in a word, affect the philosophy of existence of boards in providing autonomy of universities. "To herd all universities with one stick, in lump sum, say, sending this to the university for approval, no! Practically it has prevented the boards from the ability to think, or ability to plan. It's like you are tools; sit for couple of hours and say yes or no to whatever that ministry sends. This is wrong. This has taken away creativity of boards, and creativity of the university chancellor" [P4].

Only some of participants believe that these resolutions, with the aim to coordinate some issues in the country, do not diminish autonomy of UMSs. Furthermore, inability of some UMSs, particularly newly established universities, and lack of knowledge of some board members of rules and regulations necessitates these resolutions. "Well no, these are for their benefits, there is a reason that we are equating it for all universities, they are following up for it to happen" [P2].

Participants expressed hopes that these limitations will be resolved in time with implementation of some changes and adjustments. They continued that the implementation of some reforms could result performance improvement of the boards, and naturally, improvement in governance of UMSs. "I think, given time, these will be fine, 'cause the boards administrative experience in our universities is not that long'. Regulatory agencies and the government, too, are not very familiar with this anyhow-I think, in time, it'll be fine, surely, in ten years' time, boards in our universities will perform a lot better and stronger" [P12].

\section{Phase two}

a. Quantity of meetings and resolutions

Results showed boards held 1,323 meetings in 21 years, with the most in 2011 and 2010, and the least in 1995 and 1999. The trend analysis of number of meetings indicated a significantly increasing trend $(P<0.05)$. Considering the number of meetings and the number of boards, the number of meetings per university was calculated, which showed that 2010 witnessed the highest number of meetings with 3.3 per university. The lowest number in this period was in 1999 with 0.6. Also, analysis of trends of meetings per university indicated that this trend had been significantly increasing with time $(P<0.05)$. Overlay, boards issued 21,107 resolutions. The highest numbers of resolutions were issued in 2010 and 2011, and the least in 2001 and 1995. Trend analysis of the number of resolutions showed a significantly increasing trend $(P<0.05)$.

Considering the number of resolutions, and also the number of independent boards each year, the number of resolutions per university was calculated, which showed the highest capita in 2010 with 65.4 resolutions per university, and the least in 2001 with 6.5 resolutions. Also, results of trend of resolutions 
per university declared that this trend had been significantly increasing with time $(P<0.05)$.

On the other hand, considering the total number of resolutions and also regular meetings held each year, the number of resolution per meeting for each year was calculated, and results indicated that in 2005 the highest number of resolution per meeting (24.3), while it was the least in 2001 (7.4). Analysis of trend of resolutions per meetings showed this trend had significantly increased with time $(P<0.05)$.

More details about the number of board's meeting and resolution are presented in Table 1.

\section{Quality of resolutions}

Content analysis of resolutions revealed that most of the decisions of the UMSs boards (74.5\%) belonged to operational issues. The share of resolutions dealing with strategic and policy-making had been low (25.5\%).

In terms of nature of resolutions, many were dedicated to administrative affairs (55.4\%). Only a small percentage of resolutions dealt with the two main missions of universities; higher education (education and research) (26.9\%) and provision of health services (15.9\%).

Given the source, analysis of resolutions showed majority of resolutions $(71 \%)$ entered meetings through specific meeting agendas and decisions were made about them. The share of resolutions derived from general or national agendas was very limited (29\%).

The trends analysis of resolution was also revealed significantly increasing trend of strategic resolutions and significantly decreasing trend in operational resolutions $(P<0.05)$. Additionally, the significant increasing trend of general resolutions and decreasing trend of specific resolutions were also observed $(P<0.05)$.

\section{Discussion}

This study intended to evaluate performance of UMSs boards. Results of this study help to provide a picture of boards' activities and identify their most important performance strengths and weaknesses. In this section, our study results are presented and compared with results of similar studies.

An increasing trend was observed in terms of quantity of meetings and resolutions of UMSs boards. It seems Article 49 of the Fourth Program Act and Article 20 of the Fifth Program Act and gradual dominance of autonomy paradigm of universities and importance of the place and role of boards, were the most important reinforcements in performance of these boards. The same situation in improvement of quantitative performance has been reported in performance of boards of the Ministry of Science Universities, as well. These studies, while noting the relative increase in number of meetings and resolutions, consider the reasons for this increase such as better board members' understanding of university, creating gradual common understanding of governance of universities, better understanding of managers and board members of university problems, and more

Table 1. The number of meetings and resolutions of studied universities' boards

\begin{tabular}{|c|c|c|c|c|c|c|}
\hline \multirow[b]{2}{*}{ Year } & \multicolumn{3}{|c|}{ Number of } & \multirow{2}{*}{$\begin{array}{l}\text { Meeting per board } \\
\text { (B/A) }\end{array}$} & \multirow{2}{*}{$\begin{array}{l}\text { Resolutions per board } \\
\text { (C/A) }\end{array}$} & \multirow{2}{*}{$\begin{array}{l}\text { Resolutions per meeting } \\
\text { (C/B) }\end{array}$} \\
\hline & $\begin{array}{l}\text { Boards } \\
\text { (A) }\end{array}$ & $\begin{array}{l}\text { Meetings } \\
\text { (B) }\end{array}$ & $\begin{array}{l}\text { Resolutions } \\
\text { (C) }\end{array}$ & & & \\
\hline 1991 & 30 & 52 & 438 & 1.7 & 14.6 & 8.4 \\
\hline 1992 & 32 & 47 & 407 & 1.5 & 12.7 & 8.7 \\
\hline 1993 & 35 & 46 & 433 & 1.3 & 12.4 & 9.4 \\
\hline 1994 & 36 & 34 & 351 & 0.9 & 9.8 & 10.3 \\
\hline 1995 & 37 & 25 & 293 & 0.7 & 7.9 & 11.7 \\
\hline 1996 & 40 & 32 & 423 & 0.8 & 10.6 & 13.2 \\
\hline 1997 & 41 & 28 & 371 & 0.7 & 9.0 & 13.3 \\
\hline 1998 & 41 & 29 & 406 & 0.7 & 9.9 & 14.0 \\
\hline 1999 & 42 & 26 & 324 & 0.6 & 7.7 & 12.5 \\
\hline 2000 & 42 & 58 & 431 & 1.4 & 10.3 & 7.4 \\
\hline 2001 & 43 & 29 & 280 & 0.7 & 6.5 & 9.7 \\
\hline 2002 & 43 & 43 & 445 & 1.0 & 10.3 & 10.3 \\
\hline 2003 & 43 & 43 & 640 & 1.0 & 14.9 & 14.9 \\
\hline 2004 & 43 & 50 & 1003 & 1.2 & 23.3 & 20.1 \\
\hline 2005 & 44 & 68 & 1653 & 1.5 & 37.6 & 24.3 \\
\hline 2006 & 44 & 117 & 1921 & 2.7 & 43.7 & 16.4 \\
\hline 2007 & 44 & 89 & 1430 & 2.0 & 32.5 & 16.1 \\
\hline 2008 & 44 & 96 & 1886 & 2.2 & 42.9 & 19.6 \\
\hline 2009 & 47 & 78 & 1664 & 1.7 & 35.4 & 21.3 \\
\hline 2010 & 49 & 142 & 3207 & 2.9 & 65.4 & 22.6 \\
\hline 2011 & 52 & 172 & 3066 & 3.3 & 59.0 & 17.8 \\
\hline
\end{tabular}


familiarity with ways of using legal capacities of boards for solving problems of the university $(14,15)$.

In terms of quality of resolutions, results showed that boards focused more on micro-managerial and operational issues in their decision-making process, and less on strategic and vital issues. Some previous studies have also reported same findings $(14,16,17)$. It seems non-strategic decisions is one of the common weaknesses of boards (18). Weakness in strategic issues could have a variety of reasons. In a study by the NHS confederation imposed central (common) meeting agendas that focused more on short term objectives and routine operational issues was identified as the main reason for this weakness. Such agenda reduces the level of constructive discussion and debate in meetings, and lowers the strategic thought process in members, as well (17). In the present study, this weakness could be due to lack of intra- and extraorganizational awareness of position, role, and authority of UMSs boards. This lack of awareness has impeded the boards to consider strategic and greater governance issues, and has turned the decisions more biased toward current and routine issues. Fortunately, the analysis indicates a change of direction toward strategic decisions-making.

This change of direction happened in light of two main reasons. First, as time went by the perception of the position and the role of the boards in university governance got improved and the responsiveness and accountability of the boards became more highlighted. Therefore, the board members recognized that if they wanted to act as active members of the board and helped the board to perform more effectively, they should focus on their foremost responsibilities and tasks, which are strategic in nature. To gain a better understanding of these tasks, more orientation and training programs relating to the board's roles and responsibilities were requested. The implementation of such program resulted in the boards becoming more familiar with their roles. Hence, they paid greater attention to more strategic issues instead of spending the board's time on trivial matters.

Second, the boards were encouraged and supported to hold their own meetings themselves without the necessity of presence of attendance by MoHME representatives. This provided a chance for decreasing the number of central agendas that focused more on operational issues as well as reducing the level of non-constructive discussions and debates at meetings. Therefore, board members tended to work more on strategic issues and matters of vital importance to their universities.

Regarding quality of resolutions, results indicated more focus on administrative decisions, particularly management of financial resources, by the boards. A similar situation is observed in previous studies $(14,19)$. Accordingly, it can be concluded boards did not fully utilized their own capabilities and authorities. This weakness shows the need for full understanding of responsibilities and authorities of boards by their members, and also changes of direction of decisions made by boards toward education and research issues, and provision of health services.

Furthermore, the findings related to quality of resolutions show that common resolutions have more share. Some consider this increase favorable, and some others consider it unfavorable. Therefore, it seems finding solutions about directing the resolutions toward common or specific types is needed. It perhaps appears necessary to have regional and national boards alongside university boards in order to cover two main missions of UMSs. In this case, each UMS has its own board focusing only on specific issues of the university and so directing the resolution toward specific type. Then those UMSs, located in the same region, have a board which is called the regional board. The members of this board are selected from trustees of the involving UMSs. This regional board focuses on issues that the UMSs of that region deal with. Lastly, there is a national board that its members are selected from trustees of all regional boards. The goal of this board is to concentrate only on those issues which are common between all UMSs and hence it can direct the resolution toward common type. Therefore, not only the authority of each UMS boards is not limited by imposing them to central and common agenda, but also it will increase and highlight the main role in university governance.

Generally, the results of the present study are indicative of qualitative and quantitative improvement of UMSs boards' performance. But, since this improvement in performance has occurred over a long period, it seems necessary to accelerate changes, and respond timely, as stated in previous studies (15). On the basis of findings of this study and identified strengths and weaknesses, the following strategies are recommended for improving performance of UMSs boards:

- More delegation of authorities for the boards

- Reinforcing position of the boards

- Changing job description of boards

- Diversity in composition of boards

\section{Acknowledgements}

This work was part of $\mathrm{PhD}$ dissertation supported by Iran University of Medical Sciences [grant number 1390/628]. To carry out this study, we greatly appreciate the MoHME, the board members of medical universities and all of the officers in charge of board's secretariats who have actively participated in this study. Special thanks go to Dr. Steve O. Michael, Miss. Fahimeh Doost Nikche, Mrs. Paridokht Totonchian and Miss. Fereshte Mehrabi for their supporting efforts.

\section{Ethical issues}

The study was approved by the ethic committee of Iran University of Medical sciences.

\section{Competing interests}

The authors declare that they have no competing interests.

\section{Authors' contributions}

Authors contributed to the publication of this article as follows: study concept and design (HSS and MM); analysis and interpretation of data (HSS, MM, MH, and $\mathrm{HR}$ ); drafting of manuscript (HSS); critical revision of the manuscript (MM, $\mathrm{HR}, \mathrm{HF}, \mathrm{HA}$, and $\mathrm{MH}$ ). 
Authors' affiliations

${ }^{1}$ Health Management and Economics Research Center, Isfahan University of Medical Sciences, Isfahan, Iran. ${ }^{2}$ Department of Health Services Management, School of Management and Information Sciences, Iran University of Medical Sciences, Tehran, Iran. ${ }^{3}$ Ministry of Health and Medical Education, Tehran, Iran. ${ }^{4}$ Chancellor Office , Isfahan University of Medical Sciences, Isfahan, Iran.

\section{References}

1. World Health Organization (WHO). The World Health Report 2000 - Health Systems: Improving Performance. Geneva: WHO; 2000.

2. Mehrdad R. Health system in Iran. International Medical Community 2009; 52: 69-73.

3. Balser JR, Marx ER, Manning JF. Contemporary challenges in academic health science center financial management [internet]. [cited 2013 July]. Available from: https://www.radcliffehealth. com/sites/radcliffehealth.com/files/samplechapter/wartman chapt 04.pdf

4. Wietecha M, Lipstein SH, Rabkin MT. Governance of the academic health center: Striking the balance between service and scholarship. Acad Med 2009; 84: 170-6. doi: 10.1097/ acm.0b013e3181938d94

5. Armstrong A, Unger Z. Assessment, evaluation and improvement of university council performance. Evaluation Journal of Australasia 2009; 9: 46-54.

6. Kezar AJ. Rethinking public higher education governing boards' performance: Results of a national study of governing boards in the United States. Journal of Higher Education 2006; 77: 9681008. doi: 10.1353/jhe.2006.0051

7. Estermann T, Nokkala T, Steinel M. University autonomy in Europe II. The Scorecard Brussels: European University Association; 2011.

8. Michael SO, Schwartz M. Perceived role of trustees: A study of higher education institutions in Ohio. Journal of Educational Administration 1999; 37: 165-83. doi: 10.1108/09578239910263042

9. Varghese N, Martin M. Governance Reforms and University
Autonomy in Asia. Paris: International Institute for Educational Planning; 2013.

10. Collier J. Measuring and evaluating board performance. Measuring Business Excellence 2004; 8: 12-7. doi: $10.1108 / 13683040410555573$

11. Kiel GC, Nicholson GJ. Evaluating boards and directors. Corporate Governance: An International Review 2005; 13: 61330. doi: 10.1111/j.1467-8683.2005.00455.x

12. Minichilli A, Gabrielsson J, Huse M. Board evaluations: making a fit between the purpose and the system. Corporate Governance: An International Review 2007; 15: 609-22. doi: 10.1111/j.14678683.2007.00591.x

13. Swiecicki J. Trends in board performance. Trustee 2011; 64: 24-6.

14. Azargashb E, Arasteh H, Sabaghian Z, Towfighi J. An Evaluation of boards of trustees' functions in public universities affiliated to ministry of science, research, and technology (1991-2006). Quarterly Journal of Research and Planning in Higher Education 2008; 13: 1-20.

15. Kaskeh S, Mohebzadegan Y. Strategic development of universities explanation of functional elements of board of trustees and trend analysis of function and combinition. Social Development and Welfare Planning 2011; 2: 165-202.

16. Ebrahimipour $\mathrm{H}$, Abolhalaj $\mathrm{M}$, Jafarisirizi $\mathrm{M}$. [Revising the organizational system and board of trustees law, enacted by the Supreme Council of Cultural Revolution of Iran]. Mashhad: Mashhad University of Medical Sciences; 2012.

17. Confederation of NHS. Effective Boards in the NHS? A Study of their Behaviour and Culture. London: NHS Confederation; 2005.

18. Davis JA, Batchelor SA. The Effective College and University Board: A Report of a National Survey of Trustees and Presidents. Washington, DC: Association of Governing Boards of Universities and Colleges; 1974.

19. Damari B, Aminlou H, Farzan H, Rahbari M, Alikhani S. Ways to improve the current performance of the boards of trustees of Medical Universities in Iran. Iran J Public Health 2013; 42: 36-41. 